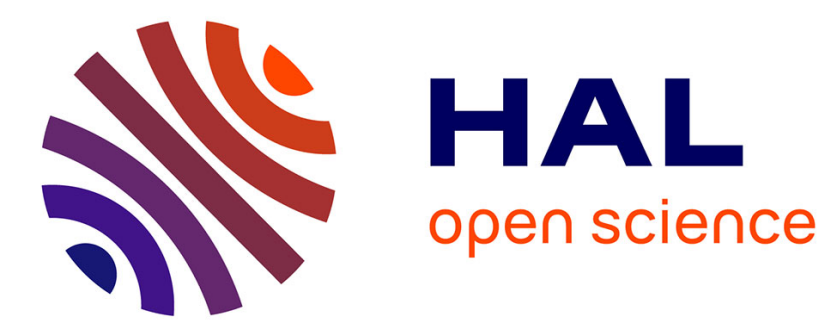

\title{
A 5-GHz Fully Integrated Full PMOS Low-Phase-Noise LC VCO
}

Giuseppe de Astis, David Cordeau, Jean-Marie Paillot, L. Dascalescu

\section{To cite this version:}

Giuseppe de Astis, David Cordeau, Jean-Marie Paillot, L. Dascalescu. A 5-GHz Fully Integrated Full PMOS Low-Phase-Noise LC VCO. IEEE Journal of Solid-State Circuits, 2005, 40 (10), pp.2087-2091. 10.1109/JSSC.2005.854601 . hal-00683329

\section{HAL Id: hal-00683329 \\ https://hal.science/hal-00683329}

Submitted on 28 Mar 2012

HAL is a multi-disciplinary open access archive for the deposit and dissemination of scientific research documents, whether they are published or not. The documents may come from teaching and research institutions in France or abroad, or from public or private research centers.
L'archive ouverte pluridisciplinaire HAL, est destinée au dépôt et à la diffusion de documents scientifiques de niveau recherche, publiés ou non, émanant des établissements d'enseignement et de recherche français ou étrangers, des laboratoires publics ou privés. 


\title{
A 5-GHz Fully Integrated Full PMOS Low-Phase-Noise LC VCO
}

\author{
Giuseppe De Astis, Member, IEEE, David Cordeau, Member, IEEE, Jean-Marie Paillot, Member, IEEE, and \\ Lucian Dascalescu, Senior Member, IEEE
}

\begin{abstract}
A 5-GHz fully integrated, full PMOS, low-phase-noise and low-power differential voltage-controlled oscillator (VCO) is presented. This circuit is implemented in a $0.35-\mu \mathrm{m}$ four-metal BiCMOS SiGe process. At $2.7-\mathrm{V}$ power supply voltage and a total power dissipation of only $13.5 \mathrm{~mW}$, the proposed VCO features a worst case phase noise of $-97 \mathrm{dBc} / \mathrm{Hz}$ and $-117 \mathrm{dBc} / \mathrm{Hz}$ at $100 \mathrm{kHz}$ and $1 \mathrm{MHz}$ frequency offset, respectively. The oscillator is tuned from 5.13 to $5.68 \mathrm{GHz}$ with a tuning voltage varying from 0 to $2.7 \mathrm{~V}$.
\end{abstract}

Index Terms-Cyclostationary noise, design method, phase noise, PMOS, symmetric center-tapped inductor, varactors, voltage-controlled oscillator (VCO).

\section{INTRODUCTION}

I NCREASING pressure for lower power, higher integration, and lower cost in the mobile communication market will, in the near future, drive industry to "on-chip" solutions. This will be made possible by the continuous scaling down of CMOS processes which allows the use of MOSFETs for low-noise applications up to microwave frequencies. Indeed, the substrate resistivity of such technologies is now close to what is obtainable with a BiCMOS SiGe technology. Also, the $f_{T}$ of the MOS transistors increases with decreasing geometry.

In this context, this work presents the design of an original 5-GHz, full PMOS, low-phase-noise and low-power differential voltage-controlled oscillator (VCO) using a $0.35-\mu \mathrm{m}$ BiCMOS SiGe process of Jazz Semiconductor. The feasibility of such a high-performance high-frequency VCO with only pMOS transistors, with $f_{T}(16 \mathrm{GHz})$ much lower than that possible with advanced CMOS processes, is demonstrated.

This paper is organized as follows. Section II treats the circuit design with two subsections concerning the design method used to minimize the phase noise and the VCO core design. Section III presents the implementation and measurement results, followed by the conclusion in Section IV.

\section{Circuit Design}

\section{A. Phase Noise Minimization}

From the well-known Leeson model [1], it can be concluded that the loaded quality factor $Q$ of the tank needs to be maximized

Manuscript received February 22, 2005; revised June 14, 2005.

M. G. De Astis is with RuSS, 70037 Ruvo Di Puglia, BA, Italy (e-mail: giuseppe.deastis@libero.it).

M. D. Cordeau is with ACCO, 78100 Saint-Germain-en-Laye, France (e-mail: david.cordeau@acco-ic.com).

M. J. M. Paillot and L. Dascalescu are with IUT Angoulême, Laboratoire d'Automatique et d'Informatique Industrielle-ESIP, UPRES_EA 1219, 16021 Angoulême, France (e-mail: jmpaillot@iutang.univ-poitiers.fr; ldascalescu@iutang.univ-poitiers.fr).

Digital Object Identifier 10.1109/JSSC.2005.854601 in order to reduce phase noise. Unfortunately, the integration of a high- $Q L C$ tank is not easy because of the medium resistivity of Silicon substrate $(\approx 10 \Omega \cdot \mathrm{cm})$. In the same way, this model recommends to maximize the dissipated power in the resistive part of the resonator, which is related to the added power of the oscillator amplifier [2]. In other words, the voltage swing across the resonator needs to be maximized, without entering the triode region of the MOS transistor. However, in most cases, the dominant noise contributor in oscillators or VCOs is the collector shot noise for bipolar transistors and channel noise for CMOS transistors [3], [4]. These cyclostationary noise sources have been related to waveform signals. Indeed, according to the linear time-varying phase noise theory of Hajimiri [5], the total single sideband phase noise spectral density in $\mathrm{dBc} / \mathrm{Hz}$ due to one current noise source on one node of the circuit at an offset frequency $\Delta \omega$ is given by

$$
L(\Delta \omega)=10 \cdot \log \left(\frac{\left(\overline{i_{n}^{2}} / \Delta f\right) \cdot \Gamma_{\mathrm{rms}}^{2}}{2 \cdot q_{\max }^{2} \cdot \Delta \omega^{2}}\right)
$$

where $\overline{i_{n}^{2}} / \Delta f$ is the power spectral density of the current noise source in question, $\Gamma_{\mathrm{rms}}^{2}$ is the rms value of the impulse sensitivity function (ISF) associated with the noise source considered previously, and $q_{\max }$ is the maximum charge swing across the current noise source. Considering that a white cyclostationary noise current can be written as the product of a white stationary process and a deterministic periodic function $\alpha(x)$ describing the noise amplitude modulation and strongly correlated with currents waveforms of the oscillator, the cyclostationary noise can be treated as a stationary noise by introducing the effective ISF given by

$$
\Gamma_{\mathrm{eff}}(x)=\Gamma(x) \alpha(x)
$$

Thus, the phase noise due to the cyclostationary current noise source is expressed by (1) replacing $\Gamma_{\mathrm{rms}}^{2}$ by $\Gamma_{\mathrm{eff}, \mathrm{rms}}^{2}$. Consequently, $\Gamma_{\text {eff,rms }}$ needs to be minimized in order to reduce phase noise significantly. In other words, the transistor would remain off almost all of the time, waking up periodically to deliver an impulse of current at the signal peak of the oscillator, where the ISF $(\Gamma(x))$ has its minimum value [6]. This induces a class-C operation of the active element within the VCO. Thus, the design method used to minimize the phase noise of the VCO consists essentially in optimizing the circuit for a class-C operation of the active part with a maximum voltage swing across the resonator. 


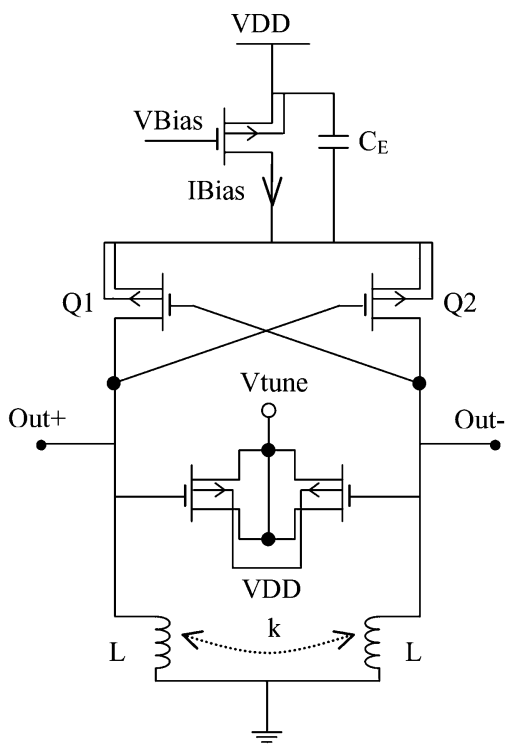

Fig. 1. VCO schematic.

\section{B. VCO Core Design}

Fig. 1 shows the VCO schematic using a cross-coupled pMOS differential topology which is the complementary structure to the well-known "nMOS only" architecture. A tail capacitor $\mathrm{C}_{E}$ is used to attenuate both the high-frequency noise components of the tail current and the voltage variations on the tail node. This latter effect results in more symmetric waveforms and smaller harmonic distortion in VCO outputs. Thus, the most significant remaining noise component of the tail current noise source is the upconversion of the flicker noise [7]. In this condition, the use of a pMOS tail-current source is justified since the pMOS transistors have lower $1 / f$ noise than the nMOS [8], [9]. In addition, one must increase the width and the length of the pMOS tail transistor to further reduce the flicker noise which lowers significantly the close-in phase noise of the VCO [8]. Furthermore, this capacitor provides an alternative path for the tail current and, consequently, if the capacitor is large enough, the transistors of the differential pair might carry very little current for a fraction of the cycle [7]. Thus, the duty cycle of the drain current waveform is significantly reduced. This effect is very important since it reduces the drain current noise injection during the zero-crossing of the tank differential voltage (i.e., when the ISF is maximum). Consequently, this behavior is consistent with an improvement of the phase noise performances of the VCO as explained in the previous subsection.

The use of a symmetric center-tapped inductor as opposed to two "uncoupled" inductors exploits the benefits of the coupling factor $k$ to increase the inductance value and can lead to a saving in chip area. Furthermore, it is now well known that a higher peak quality factor can be achieved by exciting an inductor differentially rather than single-endedly [10].

This inductor was fabricated with the last metal level, which presents a low resistivity $(10 \mathrm{~m} \Omega / \mathrm{sq}$.). The layout of the center-tapped inductor is shown in Fig. 2 and Fig. 3 shows its broadband three-port equivalent circuit model. As shown in

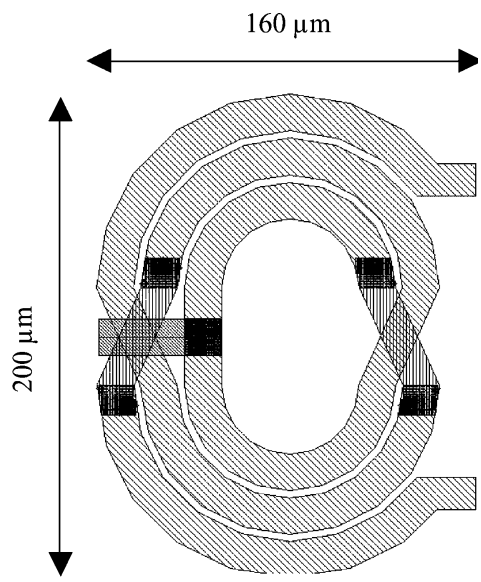

Fig. 2. Layout of the center-tapped inductor.

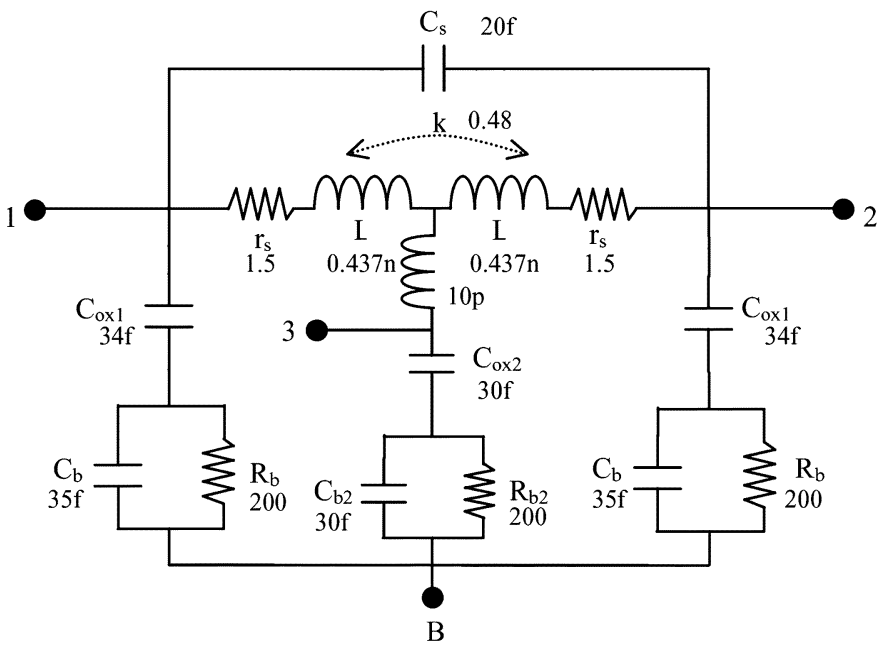

Fig. 3. Lumped circuit model of the inductor.

this figure, the global inductance value is about $1.3 \mathrm{nH}$. Both the single-ended quality factor

$$
Q=-\frac{\operatorname{Im}\left(Y_{11}\right)}{\operatorname{Re}\left(Y_{11}\right)}
$$

and differential quality factor

$$
Q_{\text {diff }}=\frac{\operatorname{Im}\left(Z_{11}+Z_{22}-Z_{12}-Z_{21}\right)}{\operatorname{Re}\left(Z_{11}+Z_{22}-Z_{12}-Z_{21}\right)}
$$

are evaluated and plotted in Fig. 4. As shown in this figure, the associated differential $Q$ factor of the symmetric center-tapped inductor is estimated to be in the range of 12 to 13 at $5 \mathrm{GHz}$. Furthermore, let us note that an improvement of the maximum $Q$ factor of about $30 \%$ for the inductor driven differentially over that of the same inductor driven single-endedly is observed.

PMOS varactors are used in inversion mode because of the wide capacitor variation that can be obtained with a low variation of source to gate bias voltage [11]. Consequently, the use of MOS varactors is consistent with the new CMOS technologies because of the low supply voltage required.

The tail-current value (IBias) is maximized while maintaining a current-limited mode of operation since, in this mode, the voltage swing across the resonator is proportional to the 


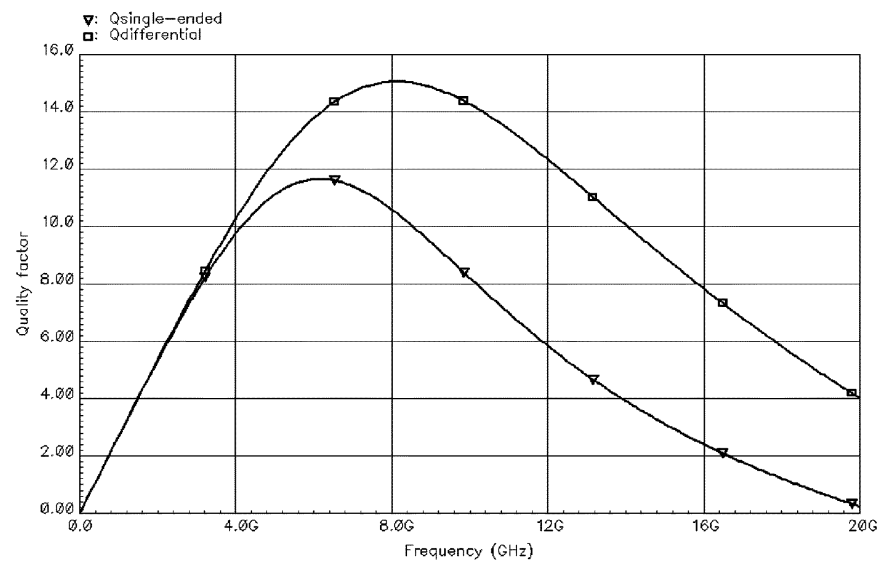

Fig. 4. Simulated $Q$ factor of the inductor driven single-endedly versus differentially.

tail-current and the tank equivalent resistance [4], [7]. Transistors Q1 and Q2 are properly sized to obtain a large enough transconductance value to ensure proper startup of the VCO but sufficiently small to reduce thermal noise.

\section{IMPLEMENTATION AND MEASUREMENT RESUlTS}

A $0.35-\mu \mathrm{m}$ BiCMOS SiGe process, which provides four metal layers with a $3-\mu \mathrm{m}$-thick top metal, is used to implement the oscillator. Fig. 5 shows the microphotograph of the fabricated VCO whose size is only $300 * 650 \mu \mathrm{m}^{2}$. During the layout, we have focus on the symmetry of the balanced circuit. For frequency measurements, an Agilent E4407B spectrum analyzer is used. The tuning characteristic of the VCO for different bias currents is shown in Fig. 6. As expected in simulations, the VCO is tuned from roughly 5.13 to $5.68 \mathrm{GHz}$ with a tuning voltage varying from 0 to $2.7 \mathrm{~V}$. As the slope of the characteristic is relatively linear between 0.5 and $1.5 \mathrm{~V}$, the VCO is suited for frequency synthesizer realization (PLL). Unfortunately, the steep slope of the tuning characteristic leads to the undesirable effect of higher VCO gain even if this can be compensated by connecting in parallel one or more pMOS varactors biased at different voltages to linearize the $C(V)$ characteristic of the resulting varactor [12]. Furthermore, due to the complementary nature of this $\mathrm{VCO}$, the frequency decreases with an increase of the tuning voltage. Thus, for use in a conventional PLL architecture, the input of the charge pump must be inverted. Fig. 7 shows the tuning characteristic of the $\mathrm{VCO}$ for different supply voltages. As shown in this figure, for a tuning voltage of $1 \mathrm{~V}$, the maximum variation of the oscillation frequency is only $34 \mathrm{MHz}$ for a supply voltage varying from 2.5 to $3.3 \mathrm{~V}$. Furthermore, temperature measurements between $-40^{\circ} \mathrm{C}$ and $80^{\circ} \mathrm{C}$ have shown a variation of the oscillation frequency of only $5 \%$ in the worst case confirming the excellent robustness of this circuit.

Phase noise was measured using the delay line method and a battery is used as supply voltage to avoid external parasitic signals. Fig. 8 shows the plot of the measured phase noise at $100 \mathrm{kHz}$ frequency offset versus the tuning voltage and Fig. 9 shows the plot of the phase noise versus offset frequency for a tuning voltage of $0.5 \mathrm{~V}$.

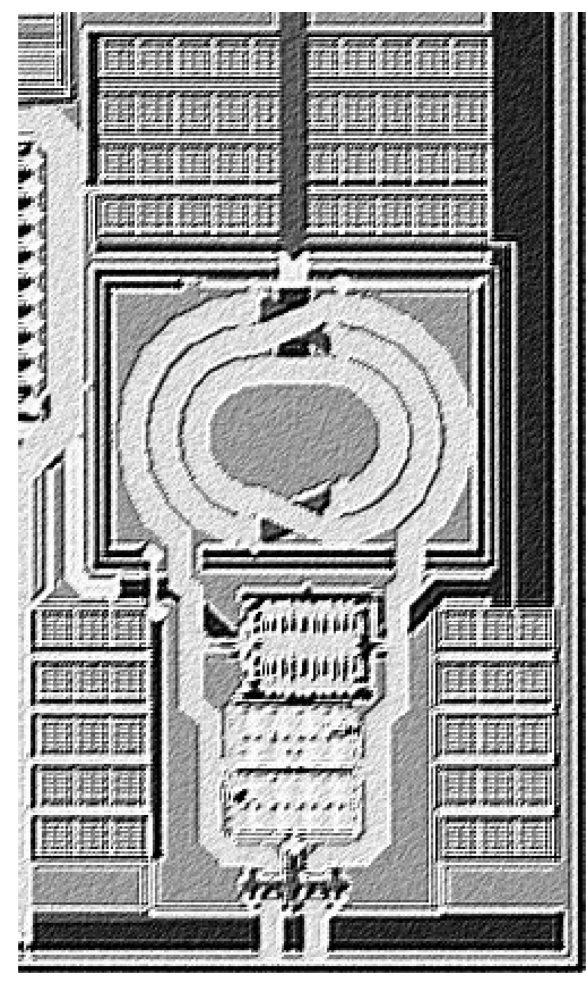

Fig. 5. 5-GHz VCO microphotograph.

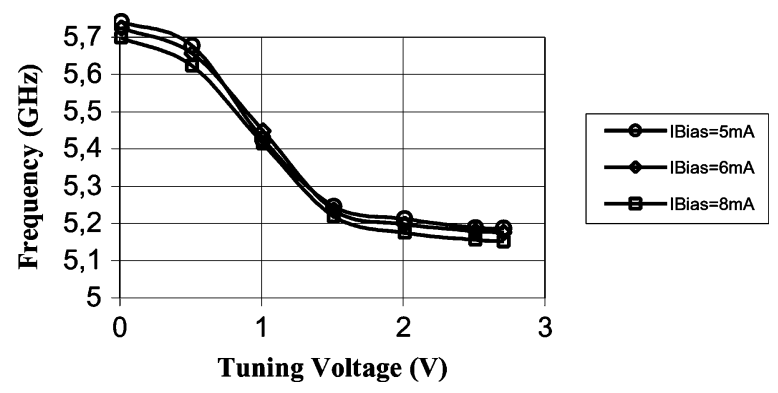

Fig. 6. Tuning characteristic of the VCO for different bias currents.

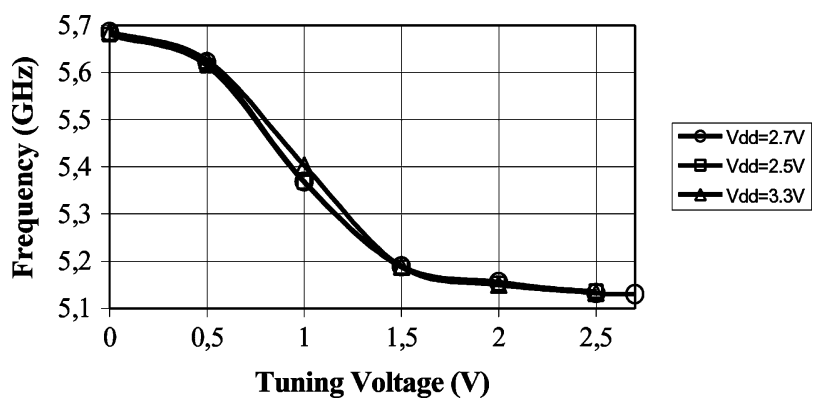

Fig. 7. Tuning characteristic for different supply voltages.

As shown in those two figures, the VCO features a worst case phase noise of $-97 \mathrm{dBc} / \mathrm{Hz}$ and $-117 \mathrm{dBc} / \mathrm{Hz}$ at $100 \mathrm{kHz}$ and $1 \mathrm{MHz}$ frequency offset, respectively. A figure of merit (FOM) has been defined in [13] to compare VCOs performances

$\mathrm{FOM}=L(\Delta \omega)[\mathrm{dBc} / \mathrm{Hz}]+10 \cdot \log \left(P_{\mathrm{DC}}[\mathrm{mW}]\right)-20 \cdot \log \left(\frac{\omega_{0}}{\Delta \omega}\right)$ 


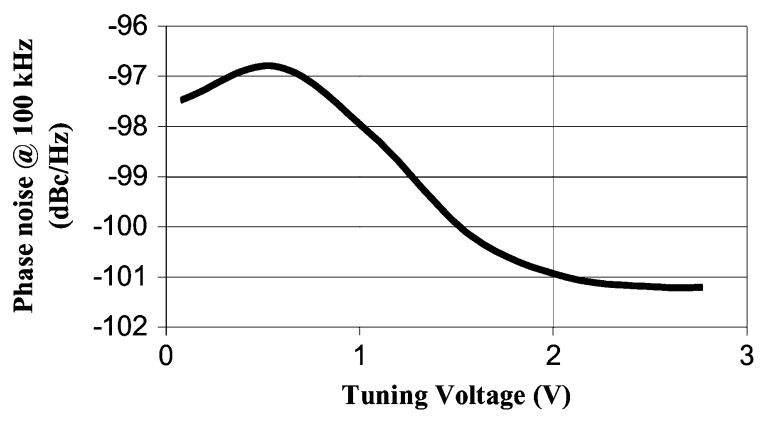

Fig. 8. Measured phase noise at $100 \mathrm{kHz}$ versus tuning voltage.

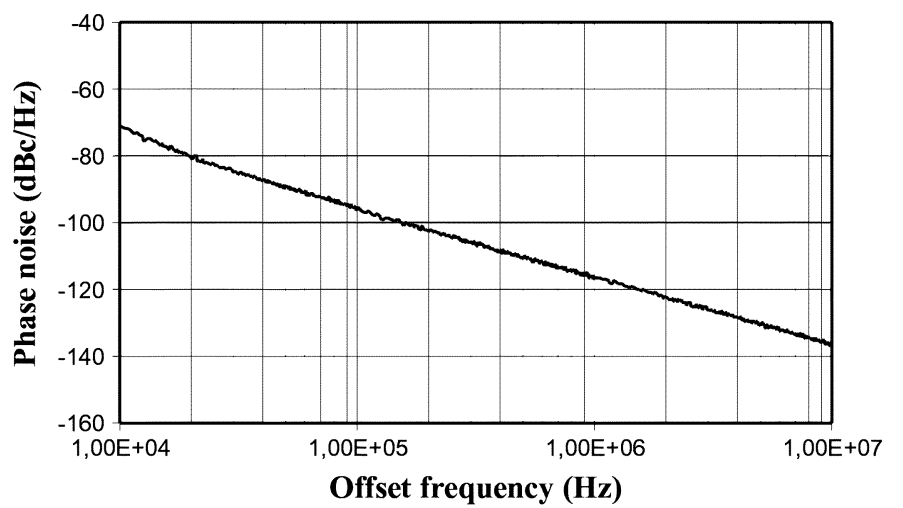

Fig. 9. Measured phase noise of the VCO for a tuning voltage of $0.5 \mathrm{~V}$.

TABLE I

VCO PERFORMANCES COMPARISON

\begin{tabular}{|c|c|c|c|c|c|}
\hline VCO & Tech. & $\begin{array}{c}\text { Frequency } \\
{[\mathrm{GHz}]}\end{array}$ & $\begin{array}{c}\text { Power } \\
{[\mathrm{mW}]}\end{array}$ & $\begin{array}{c}\text { PN } \\
{[\mathrm{dBc} / \mathrm{Hz}]}\end{array}$ & $\begin{array}{c}\text { FOM } \\
{[\mathrm{dBc} / \mathrm{Hz}]}\end{array}$ \\
\hline$[14]$ & $\begin{array}{c}0.18 \mu \mathrm{m} \\
\mathrm{CMOS}\end{array}$ & 5.8 & 8.1 & $\begin{array}{c}-110 @ 1 \\
\mathrm{MHz}\end{array}$ & -176 \\
\hline$[9]$ & $\begin{array}{c}0.24 \mu \mathrm{m} \\
\mathrm{CMOS}\end{array}$ & 5.8 & 5 & $\begin{array}{c}-112 @ 1 \\
\mathrm{MHz}\end{array}$ & -180 \\
\hline$[15]$ & $\begin{array}{c}\text { BiCMOS } \\
0.35 \mu \mathrm{m}\end{array}$ & 1.91 & 10 & $\begin{array}{c}-121 @ \\
600 \mathrm{kHz}\end{array}$ & -176.6 \\
\hline $\begin{array}{c}\text { (this } \\
\text { work) }\end{array}$ & $\begin{array}{c}\text { BiCMOS } \\
\text { SiGe 0.35 }\end{array}$ & 5.6 & 13.5 & $\begin{array}{c}-117 @ 1 \\
\mathrm{MHz}\end{array}$ & -180 \\
\hline
\end{tabular}

where $L(\Delta \omega)$ is the total single sideband phase noise spectral density at an offset frequency $\Delta \omega, P_{\mathrm{DC}}$ is total VCO power consumption, and $\omega_{0}$ is the pulsation of oscillation. This results in a FOM of -180 for this design.

In Table I, some recently published VCOs are listed. As shown in this table, our results compare favorably to other recently published fully integrated VCO performances. The measured performances of this $5-\mathrm{GHz}$, fully integrated, full pMOS VCO are summarized in Table II.

\section{CONCLUSION}

The feasibility of a high-performance, high-frequency, fully integrated VCO with only pMOS transistor with poor $f_{T}(16 \mathrm{GHz})$ is demonstrated in this paper. The fabricated VCO is tuned from 5.13 to $5.68 \mathrm{GHz}$ with a tuning voltage varying from 0 to $2.7 \mathrm{~V}$. The phase noise of the oscillator was optimized by taking into account for cyclostationary noise phenomena. Measured worst case phase noise is $-97 \mathrm{dBc} / \mathrm{Hz}$
TABLE II

5-GHz VCO MEASUREd PERFORMANCES SUMmaRY

\begin{tabular}{|c|c|}
\hline Supply Voltage (V) & 2.7 \\
\hline Power Consumption (mW) & 13.5 \\
\hline Area $\left(\mu \mathrm{m}^{2}\right)$ & $300 * 650$ \\
\hline Tuning Range (MHz) & 550 \\
\hline Tuning Voltage (V) & $0-2.7$ \\
\hline$F_{0}(\mathrm{GHz})$ & 5.4 \\
\hline $\begin{array}{c}\text { Phase Noise @ } 100 \mathrm{kHz} \\
\text { (dBc/Hz) at } 5.6 \mathrm{GHz}\end{array}$ & -97 \\
\hline $\begin{array}{l}\text { Phase Noise @ } 1 \mathrm{MHz} \\
\text { (dBc/Hz) at 5.6 GHz }\end{array}$ & -117 \\
\hline
\end{tabular}

and $-117 \mathrm{dBc} / \mathrm{Hz}$ at $100 \mathrm{kHz}$ and $1 \mathrm{MHz}$ frequency offset, respectively, under $2.7-\mathrm{V}$ power supply voltage with only $5-\mathrm{mA}$ current consumption.

\section{ACKNOWLEDGMENT}

The authors wish to acknowledge P. Colestock from Jazz Semiconductor and O. Llopis and G. Cibiel from the LAASCNRS for phase noise measurements.

\section{REFERENCES}

[1] D. B. Leeson, "A simple model of feedback oscillator noise spectrum," Proc. IEEE, vol. 54, no. 2, pp. 329-330, Feb. 1966.

[2] M. Prigent, M. Camiade, J. C. Nallatamby, J. Guittard, and J. Obregon, "An efficient design method of microwave oscillator circuits for minimum phase noise," IEEE Trans. Microw. Theory Tech., vol. 47, no. 7, pp. 1122-1125, Jul. 1999.

[3] M. A. Margarit, J. L. Julian Tham, R. G. Meyer, and M. J. Deen, “A lownoise, low-power VCO with automatic amplitude control for wireless applications," IEEE J. Solid-State Circuits, vol. 34, no. 6, pp. 761-771, Jun. 1999

[4] R. Aparicio and A. Hajimiri, "A noise-shifting differential Colpitts VCO," IEEE J. Solid-State Circuits, vol. 37, no. 12, pp. 1728-1736, Dec. 2002.

[5] A. Hajimiri and T. H. Lee, "A general theory of phase noise in electrical oscillators," IEEE J. Solid-State Circuits, vol. 33, no. 2, pp. 179-194, Feb. 1998.

[6] T. H. Lee and A. Hajimiri, "Oscillator phase noise: A tutorial," IEEE J. Solid-State Circuits, vol. 35, no. 3, pp. 326-336, Mar. 2000.

[7] A. Hajimiri and T. H. Lee, "Design issues in CMOS differential LC oscillators," IEEE J. Solid-State Circuits, vol. 34, no. 5, pp. 717-724, May 1999.

[8] K. O. Kenneth, N. Park, and D. J. Yang, "1/f noise of nMOS and pMOS transistors and their implications to design of voltage controlled oscillators," in IEEE Radio Frequency Integrated Circuit Symp. Dig., Jun. 2002, pp. 59-62.

[9] J. Bhattacharjee, D. Mukherjee, E. Gebara, S. Nuttinck, and J. Laskar, "A 5.8 GHz fully integrated low power low phase noise CMOS LC VCO for WLAN applications," in IEEE Int. Microwave Symp. Dig., Jun. 2002, pp. 585-588.

[10] M. Danesh, J. R. Long, R. A. Hadaway, and D. L. Harame, "A Q-factor enhancement technique for MMIC inductors," in IEEE Int. Microwave Symp. Dig., vol. 1, Jun. 1998, pp. 183-186.

[11] P. Andreani and S. Mattisson, "On the use of MOS varactors in RF VCOs," IEEE J. Solid-State Circuits, vol. 35, no. 6, pp. 905-910, Jun. 2000.

[12] J. Mira, T. Divel, S. Ramet, J.-B. Begueret, and Y. Deval, "Distributed MOS varactor biasing for VCO gain equalization in $0.13 \mu \mathrm{m}$ CMOS technology," in IEEE Radio Frequency Integrated Circuits (RFIC) Symp. Dig., Jun. 2004, pp. 131-134.

[13] A. Wagemans et al., "A $3.5 \mathrm{~mW} 2.5 \mathrm{GHz}$ diversity receiver and a 1.2 $\mathrm{mW} 3.6 \mathrm{GHz} \mathrm{VCO}$ in silicon-on-anything," in IEEE ISSCC Dig. Tech. Papers, Feb. 1998, pp. 250-251. 
[14] Y.-K. Chu and H.-R. Chuang, "A fully integrated $5.8 \mathrm{GHz}$ U-NII band 0.18- $\mu \mathrm{m}$ CMOS VCO," IEEE Microw. Wireless Compon. Lett., vol. 13, no. 7, pp. 287-289, Jul. 2003.

[15] D. Ham and A. Hajimiri, "Concepts and methods in optimization of integrated LC VCOs," IEEE J. Solid-State Circuits, vol. 36, no. 6, pp. 896-909, Jun. 2001.

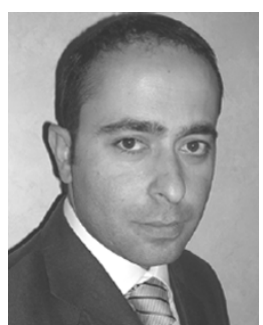

Giuseppe De Astis (M'01) was born in Ruvo di Puglia, Italy. He received the Laurea degree in electronics from the University of Pavia, Italy, in 1997, with a work on characterization of passive components for RF applications.

In 1998, he joined ATMEL for RF design development in the frame of a European project named PAPRICA. His attention was focused on the main blocks of a transceiver. In 2001, he joined ACCO as an RF and MMIC Design Engineer, where he worked on different transceivers for GSM and WLAN. In 2005, he founded RuSS (Ruvum Silicon Solutions), a consulting company aiming also at developing high-value full CMOS RF IPs. His fields of interest are synthesizers and transceivers for wireless communication in CMOS and BiCMOS technology.

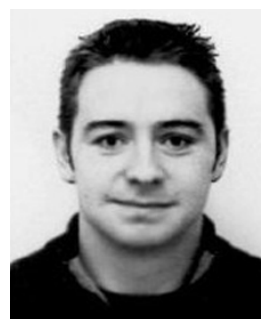

David Cordeau (S'02-M'05) was born in Civray, France, in 1977. He received the M.S. degree in electronics from the Ecole Nationale Supérieure d'Ingénieurs de Limoges, Limoges, France, in 2000, and the Ph.D. degree from the University of Poitiers, Poitiers, France, in 2004. His doctoral dissertation concerned the behavioral study and design of integrated polyphases VCOs using Si and $\mathrm{SiGe}$ technologies for radio communications.

$\mathrm{He}$ is currently with ACCO, France, where he is involved in the design of silicon RF integrated circuits.

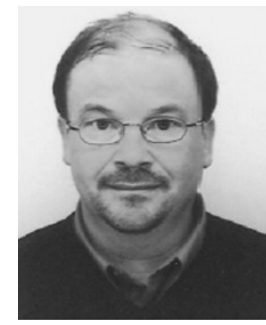

Jean-Marie Paillot (M'95) received the Ph.D. degree in electronics from the University of Limoges, France, in 1990. His thesis on the design of nonlinear analogic circuits and the study of the noise spectra of integrated oscillators was prepared at the Institute of Research for Optical Communications and Microwaves, Limoges.

After graduation, he joined the Electronics Laboratory of PHILIPS Microwave, at Limeil, as an R\&D engineer in charge of the design of analogical and numerical microwave monolithic integrated circuits Since October 1992, he is with the University Institute of Technology, Angoulême, where he currently is Professor of Electronics Engineering. In charge of several contracts with industry, and author of a couple of papers published in scientific journals, he is presently interested in phase noise reduction techniques for microwave oscillators, as well as in the research and development of switched capacitor filters in RF domain.

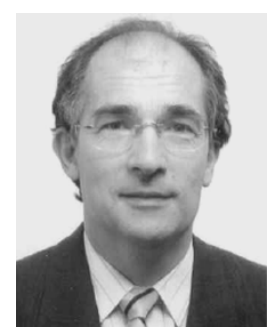

Lucian Dascalescu (M'93-SM'95) graduated with first class honors from the Faculty of Electrical Engineering, Technical University of Cluj-Napoca, Romania, in 1978, and received the Dr.Eng. degree from the Polytechnic Institute of Bucharest, Romania. He received the Dr.Sci. degree and then the Habilitation à Diriger de Recherches diploma in physics, both from the University Joseph Fourier, Grenoble, France.

In September 1997, he was appointed Professor of electrical engineering and automated systems and Head of the Electronics and Electrostatics Research Unit at the University Institute of Technology, Angoulême, France. He is the author of several textbooks in the field of electrical engineering and ionized gases. He holds 14 patents and has written more than 70 papers. His research interests include applied electrostatics and ESD.

Prof. Dascalescu is a senior member of IAS, and Vice-Chair of the Electrostatics Processes Committee. He is a member of Société des Electriciens et Electroniciens (SEE), and Club Electrotechnique, Electronique, Automatique (EEA) France. 